\title{
ESTRATÉGIAS DE CONTATO ENTRE OS CONCEITOS DE CULTURA, MEMÓRIA E IDENTIDADE
}

Sibila Rocha é professora do Centro Universitário Franciscano e doutora em Ciências da Comunicação pela Universidade do Vale dos Sinos (Unisinos).

E-mail: sibila@unifra.br

Vera Elizabeth Prola Farias é professora do Centro Universitário Franciscano e doutora em Literatura pela Universidade Federal de Santa Maria (UFSM).

E-mail: vpfarais@gmail.com

\begin{abstract}
Resumo
Discute-se o entrecruzamento dos conceitos de cultura, memória e identidade a partir de um mapeamento de formulações feitas nas últimas décadas, situando as transformações de algumas noções no contexto da crítica literária. Para caracterizar este processo de entrelaçamento, buscase reconhecer matrizes históricas que associam-se a uma competência cultural de reconhecimento levando em consideração aspectos de prática social de sentidos.
\end{abstract}

\begin{abstract}
This paper discusses the intertwining of the concepts of culture, memory and identity from a mapping formulations made in recent decades, reaching transformations of some notions in the context of literary criticism. To characterize this weaving process, we seek to recognize historical matrix that is associated with a cultural competence recognition taking into account aspects of social practice and practical sense.
\end{abstract}

\section{1) Considerações preliminares: $O$ processo histórico}

No entendimento que na história dos Estudos Culturais, os primeiros encontros foram com a crítica literária, uma vez que o valor literário havia se sedimentado como relação de força entre as culturas, o deslocamento dos estudos da literatura para a vida cotidiana estabeleceu impactos metodológicos que atingiram abordagens sedimentadas no âmbito histórico. Sob o ponto de vista político, trouxeram à tona questões intimamente vinculadas com as relações sociais e às formações de classes, evidenciando que a cultura está envolvida com o poder e com a produção de assimetrias nas capacidades dos indivíduos e dos grupos sociais. Essa posição estabelece a convicção de que é impossível abstrair a cultura das relações de poder e das estratégias de mudança social.

Raymond Williams, um dos pais dos Estudos Culturais, junto com Hoggart e Thompson, conhecidos como os founding fathers, distinguiu três sentidos modernos principais do termo "cultura". Com base em suas raízes etimológicas no trabalho rural, a palavra primeiro significa algo como civilidade. No século XVIII, torna-se mais ou menos sinônima de civilização, no sentido de um processo geral de progresso intelectual, espiritual e material com a devida correlação histórica entre conduta polida e comportamento ético (EAGLETON, 2005, p. 23).

Na virada do século XIX, a noção de cultura deixa de ser sinônimo de civilização para virar seu antônimo, quando os aspectos descritivos e normativos implícitos nesta última começam a separar-se em decorrência do atravessamento paradigmático da conotação imperialista no sentido do termo. Para Eagleton: 
A civilização era abstrata, alienada, fragmentada, mecanicista, utilitária, escrava de uma crença obtusa no progresso material; a cultura era holística, orgânica, sensível autotélica, recordável. O conflito entre cultura e civilização, assim, fazia parte de uma intensa querela entre tradição e modernidade (EAGLETON, 2005, p.23).

Ainda, sob a perspectiva de Eagleton (2005), na esteira das reflexões de Herder, a ideia de cultura, a partir do idealismo alemão, torna-se o oposto de civilidade ao assumir algo do seu significado moderno de um modo de vida característico - um ataque ao universalismo iluminista. A cultura pode, então, não significar uma narrativa grandiosa e unilinear da humanidade em seu todo, mas a diversidade de formas de vidas específicas, cada uma com regramentos próprios e peculiares.

Por outro lado, a cultura como civilização tinha tomado emprestadas suas distinções valorativas - elevado/baixo- dos primórdios da antropologia, para a qual algumas culturas eram claramente superiores a outras. Esse corpo conceitual está entranhado num processo de construção cultural, como assinalaram os pensadores de Frankfurt, que por meio de estratégias de exclusão/dominação fomentaram a construção e a manutenção de sistemas elitistas de distribuição de poder, inclusive o poder de representar e o poder de interpretar.

$\mathrm{O}$ avanço do conhecimento no século XX impulsionou o questionamento dessas posições: na contemporaneidade, nos contornos dos Estudos Culturais, constrói-se um histórico que culmina na ideia de que a "cultura comum ou ordinária" pode ser vista como um modo de vida em condições de igualdade de existência com qualquer outra. Ser simplesmente uma cultura de algum tipo já é um valor em si. Através de um olhar diferenciado sobre a História Literária, Williams mostra que essa é uma categoria chave que conecta tanto a analise literária quanto a investigação social, apontando para ela como um nível dominante da vida social. Isso pressupõe uma conexão orgânica entre a experiência vivida e as posições teóricas assumidas na crença acadêmica, um posicionamento político-intelectual.

$\mathrm{Na}$ complexidade do mercado intelectual atual, concebe-se a possibilidade de operações metodológicas plurais, no sentido de validar a leitura da literatura sob perspectivas, nas quais a palavra controla a vivência da temporalidade porque seleciona e organiza os signos. Nesse viés, a crítica literária transita da teoria literária em direção a um processo de integração interdisciplinar com várias áreas do conhecimento, especialmente entre as Ciências Humanas, fato que tem levado à ampliação de quadros teóricos. Esse processo abala a permanência de definições consensuais, desestabilizadas pela diluição de fronteiras entre os objetos de análise, antes definidas em sua especificidade.

O papel que a literatura foi desempenhando no último século, elaborando e discutindo a crise do sujeito e, portanto, da representação, instiga posições de entendimento de que a literatura tem sido o lugar do moderno, onde o pensamento contemporâneo se articulou com maior audácia, chegando às proximidades do que "nunca foi escrito, nunca foi representado", como diz Walter Benjamin.

Essa dimensão assumida pela literatura leva Roberto Vecchi (2001, p.73) a profetizar que "a história das ideias e da cultura do século XX, quando for escrita, talvez possa coincidir 
como nenhuma outra época com a história literária”. Tal tipo de apontamento fortalece posições de entrecruzamento de diferentes vias de reflexão na investigação da produção literária, que podem levar à ultrapassagem dos limites mais estreitos das fronteiras no interior dos estudos literários, permitindo a formulação de desdobramentos que agreguem conceitos de outros horizontes teóricos numa metodologia mais plural.

Cruzar identidade e cultura constitui-se hoje num topos de importância indiscutível, quando relacionado às múltiplas possibilidades da literatura como prática significante na nossa sociedade, como instância de articulação entre o imaginário e o real, como movimento (des)contínuo do ser humano que se faz sujeito inscrevendo-se nas práticas sociais. Sobretudo, implica no questionamento de categorias "rasuradas pela cultura contemporânea".

\section{2) Primeiro cenário: A ambiência para cruzamentos teóricos}

Para Antonio Cândido (1987), a tentativa de estabelecer relações entre a literatura e a história social, apesar de polêmica, e até mesmo perigosa para a análise literária, não exclui a questão de que a criação literária [...]é um sistema de produtos que são também instrumentos de comunicação entre os homens, possui tantas ligações com a vida social, que vale a pena estudar a correspondência e a interação entre ambas ( CANDIDO, 1987, p.161).

A reflexão que se impõe, para quem trabalha com a literatura numa perspectiva não exclusivamente formalista, é de abertura para a ideia da vinculação da especificidade artística às complexas relações das sociedades reais, que são, de certa forma, contingentes e substituíveis.

A proposição de Eagleton (1983) é de que a Teoria Literária deve refletir a natureza da Literatura e da Crítica Literária, e serão muitos os métodos capazes de fazê-lo, que tem mais em comum com outras disciplinas - Teoria Linguística, Sociologia, História etc. - do que entre si. Isto supõe a possibilidade, teoricamente ilimitada, de se ampliar o discurso crítico confinado à "literatura" e, no reconhecimento de que é possível falar de Teoria Literária sem perpetuarmos a ilusão de que a literatura existe como um objeto específico do conhecimento. Eagleton conclui dizendo:

Minha opinião é que seria mais útil ver a 'literatura' como um nome que as pessoas dão, de tempos em tempos e por diferentes razões, a certos tipos de escrita, dentro de todo um campo daquilo que Michel Foucault chamou de "práticas discursivas" e que se alguma coisa deva ser objeto de estudo, este deverá ser todo o campo de práticas, e não apenas as práticas por vezes rotuladas, de maneira um tanto obscura, de literatura (EAGLETON, 1983, p.220).

Tentando evitar, no entanto, que as fronteiras da Teoria da Literatura se esgarcem tanto, a ponto de perder qualquer vestígio de particularidade, o autor propõe como especificidade de seu estudo (da Literatura) a preocupação com os tipos de efeitos produzidos

pelos discursos e como eles são produzidos. Como ele mesmo reconhece, isso seria a 
recuperação da forma mais antiga da Crítica Literária, conhecida como Retórica, que examinava a maneira pela qual os discursos são constituídos a fim de se obter certos efeitos. A Retórica considerava a fala e a escrita não apenas objetos textuais, mas também formas de atividades das relações sociais, praticamente ininteligíveis fora das finalidades e condições sociais em que se situavam.

Em direção semelhante, Jameson chama a atenção para o fato de que:

a obra ou o texto não estão inseridos em um processo genético em que são entendidos como algo que surge a partir deste ou daquele momento de forma ou estilo; tampouco relacionam-se 'extrinsecamente' com um campo ou contexto que é, pelo menos inicialmente, apresentado como algo que fica além deles. Em vez disso, os dados de uma obra são questionados em termos de suas condições formais e lógicas e, particularmente, de suas condições semânticas de possibilidades (JAMESON, 1992, p.16).

No viés do pensamento do autor, a literatura é considerada como um processo nem mais nem menos misterioso que outros processos de produção cultural - apesar de ser a atividade mais autoconsciente simbolizadora da cultura - resultante, como efeito, de causas mais básicas, "causas-ausentes" que nos permitem espiar o funcionamento da roda da História.

É a amplitude da estrutura narrativa, sua capacidade de unir todas as histórias individuais, de grupos e culturas em uma única grande história coletiva, que, de uma forma difratada e simbólica, arranja os episódios vitais de uma única trama ampla e inacabada. Sua doutrina do "inconsciente político" busca os elos dessa narrativa, na recuperação para a superfície do texto da realidade reprimida e enterrada desta História fundamental, onde se borram as diferenças entre ideologia e verdade - para Jameson todas as representações da realidade são de natureza ideológica -, ainda que um tipo de ideologia conduza ao esforço de libertação do homem, e outras o condenem a um "eterno retorno" e suas "necessidades alienadoras".

Tais posições evidenciam que os debates acerca das relações entre história e Literatura - e de todos os temas residuais envolvidos - abrangem toda a tradição cultural elaborada a partir do Iluminismo e, centrada na razão, que partilha de uma ideia de "representação" baseada na concepção de "realidade", concebida em termos idealistas ou materialistas, mas intrinsecamente "real" (objetiva), distinta da consciência do sujeito; mas, principalmente, tais posições enfatizam um outro olhar, que transita amplamente na cultura contemporânea - o caráter pós (pós-estruturalismo, pós-modernismo, pós-marxismo) - repleto de variações interpretativas como resultado do "giro linguístico", a partir dos anos 60 e 70 do século XX, que se constituiu no encontro de várias correntes teóricas articuladas no pressuposto comum da "linguagem" como constituinte da "realidade". Trata-se da "crise da representação", ou seja, da ideia moderna de representação e sua substituição pelo pressuposto de que "é pelo e no discurso, como instância de articulação entre o nível linguístico e sua exterioridade, que se opera a construção/desconstrução de identidades constituídas nos textos, na história e na política (INDURSKY, 2000, p.11). 
Essas formulações permitem, sobretudo no caso das abordagens textuais, ler os imaginários sociais como constituintes da própria realidade. Segundo Mauss (APUD FALCON, 2000, p.101), "os imaginários são outros tantos marcos específicos no vasto sistema simbólico que produz toda coletividade e através do qual ela se percebe, divide e elabora". Nessa interface, as identidades "concebidas aqui como movimentos contínuos/descontínuos das relações que sujeitos, comunidades, nações e instituições estabelecem imaginariamente com o real" (INDURSKI, 2000, p.11) deslocam-se e descentram-se tanto de seu lugar no mundo social e cultural quanto de si mesmos.

Para Hall (2001), o "sujeito social” tem sua identidade formada não só na interação entre o "eu/real"; é formado e modificado na sua relação com os mundos "exteriores" e na interpelação simbólica de outras identidades. O deslocamento das estruturas sociais desarticula identidades estáveis e possibilita novas articulações (des)alojadas dos discursos

unificados. É preciso sublinhar que a construção da identidade remete para a maneira como cada um se filia no seu próprio passado e, portanto, depende da memória privada e também da coletiva.

Articular a diferença fundadora da especificidade das produções simbólicas e as dependências que as inscrevem no mundo social implica o cruzamento de enfoques que foram, durante muito tempo, alheios uns dos outros, mas cujo objeto é a descrição e a análise de formas materiais que veiculam o discurso.

Essa esfera sempre se prestou de matéria apropriada e maleável para absorver a energia do pensamento sob forma de símbolos em trajeto pelos significantes. A constituição discursiva se define pela sua relação com a formatação ideológica, isto é, os textos que fazem parte de uma estrutura discursiva remetem a uma mesma formação ideológica porquanto a formação discursiva determina o que pode e deve ser dito, a partir de um lugar historicamente determinado.

As produções simbólicas se inscrevem no mundo social a partir da visão dos sujeitos que as produzem dos componentes ideológicos de sua cultura peculiar, os quais se externalizam, principalmente pela linguagem verbal. Nesse sentido, é necessário o cruzamento entre sujeito, discurso e história, bem como a consequente reflexão em torno da formação e determinação dos sujeitos e suas representações.

\section{3) Segundo cenário: Prática social e prática de sentido}

É pelo e no discurso, como instância de articulação entre a linguagem e sua exterioridade, que se opera a construção/destruição de identidades. Para Indursky (2000) identidades são concebidas como movimentos contínuos/ descontínuos das relações que sujeitos, comunidades, nações, instituições estabelecem imaginariamente com o real, produzindo uma interface que vem garantir sua circulação e inserção dentro de certas condições sócio-históricas e discursivas que são, elas próprias: 
O paradigma da modernidade emerge a partir da conceptualização do indivíduo como centro de uma reinterpretação fundadora de autoria de si e do mundo, mas sob o impacto determinante das referências hegemônicas dos processos políticos que pautaram os sistemas da cultura ocidental. Durante a constitutiva daquelas relações. Nesse sentido, as identidades resultam de formas de subjetividade, cujas representações simbólicas são o lugar privilegiado de manifestação ideológica (INDURSKY, 2000, p.08).

Por outro lado, a memória é um fator inerente à construção de identidade na sua capacidade de filtrar e manter sentidos que atravessam o discurso enquanto espaço no qual o sujeito se constrói e se inscreve. A memória, mais do que um arquivo classificatório de informação que reinventa o passado, é um referencial norteador na construção de identidades no presente. Mas esse mecanismo só ganha existência pela simbolização que a linguagem possibilita e, se a memória é, portanto, um fator inerente à construção de identidade, o discurso é o espaço de conhecimento e de interação no qual o ser humano se faz sujeito.

$\mathrm{Na}$ modernidade, como assinalaram os pensadores da Escola de Frankfurt, forjou-se um edifício cultural através de estratégias de exclusão/dominação, fomentando a construção de sistemas elitistas de distribuição de poder, inclusive do poder de representar e de interpretar. Nesse sentido, Freda Indursky entrecruza discurso, identidade e memória como referentes de importância indiscutível para o debate relacionado com as múltiplas questões que envolvem a linguagem, pois essa discussão:

Instiga uma série de reflexões sobre a formação e determinação histórica dos sujeitos e suas representações lingüístico-ficcionais, representações essas que, acionadas pela memória emancipada, tornam consciente o que o esquecimento, na sua capacidade de impor um limite negativo ao conhecimento, suprimiu da lembrança e relegou ao esquecimento (INDURSKY, 2000, p. 08).

Fernando Catroga (2001), em seu estudo Memória e História, aponta para o fato de que a memória jamais poderá ser um mero registro, já que é uma representação afetiva feita a partir do presente dentro da tensão tridimensional do tempo. Daí seu caráter seletivo e o entendimento de que, enquanto expressão coletiva é instância solidificadora da identidade e, por isso mesmo, não escapa à instrumentalização do poder através da seleção do que se recorda e do que, consciente ou inconscientemente, se silencia.

Por extensão, toda recordação quando representada em narrativa tende a organizar, de forma coerente, o casual e os efeitos do real-passado quando foi presente, como se no caminho não houvesse esquecimento. Em outro viés, mas na mesma direção, a identidade é uma construção social dialógica entre o eu e o outro, que pressupõe cadeias de filiações identitárias, distintiva da diferença entre o indivíduo em relação aos outros, ao mesmo tempo em que impõe, em nome do "eu", deveres e lealdades que criam um sentimento de pertença a grupos ou entidades.

Assim sendo, entende-se porque é que a memória produz imagens em que se misturam história e ficção, bem como o entrelaçamento do campo factual com o campo ético e estético. Memória, então, é um produto subjetivo que não se diferencia da imaginação? Para Catroga 
(2001, pg 65), a representação imaginária pode ter, ou não, referencialidade, enquanto o ato de recordar aceita subordinar-se ao princípio da realidade, mobilizando argumentos de validação para as evocações do passado, tendo em vista garantir a fidelidade do narrado.

Esse processo tende a encobrir sua convocação seletiva do que já existe e desemboca em movimentos de transparência e/ou ocultamente narrativo, permeados pelo ato constitutivo do sujeito enquanto ser na e da cultura, e que se materializam em estruturas discursivas constituídas e não constituintes, que só podem ser interrogadas ou interpretadas ao nível do que dizem. Essa convicção aproxima-se daquela de Paul Valéry, para quem o passado é uma categoria mental moldável pela subjetividade de quem se propõe a recuperá-lo. Assim, a reconstituição de épocas passadas ancora-se em procedimentos contraditórios e escorregadios que brotam da liberdade imaginativa de reviver tempos distintos do nosso, ordenando-os e reorganizando-os a partir do presente, sob o signo de um "tempo do agora". A escrita, diz Bourdieu "retira a prática e o discurso do fluxo do tempo"( APUD HARVEY,1989). Ao que acresce Harvey $(199$, p.191) "todo sistema de representação é uma espécie de espacialização que congela automaticamente o fluxo da experiência e, ao fazê-lo, destrói o que se esforça para representar".

A memória é um referencial vivo na construção de identidades, pois, em sua capacidade de filtrar e manter o sentido atua por meio de seus processos e efeitos, os quais podem ser tanto de lembrança, de redefinição e de transformação, quanto de esquecimento, de ruptura e denegação do vivido. Esse mecanismo inerente ao ser humano, mais do que simples arquivo classificatório de informação que reinventa o passado, é um norteador na construção de identidades.

O caráter inerente de que toda representação trata de significar, através de um elemento representante, a presença de um ausente, sugere a possibilidade de "simulação", pelo discurso, onde confluem o mundo das coisas representadas e o mundo das pulsões do sujeito que as representa. Sendo assim, a "simulação", pelo discurso, aproxima significativamente os campos da ficção e da história.

As correntes teóricas da literatura do século XX construíram suas bases ou numa relação de negação/distanciamento da perspectiva histórica ou na problematização da relação possível entre Literatura e História. Especialmente, as segundas exprimiram a complexidade interseccional entre os dois campos e, ao mesmo tempo, apontaram a possibilidade de uma reflexão sobre como conceber, representar ou exprimir relações entre a vida e arte, independente das referências expressas que esta possa fazer àquela, mas dependente da experiência singular do sujeito da modernidade e de uma série de rupturas nos discursos do conhecimento moderno.

Segundo Stuart Hall (2004,p.34), a primeira ruptura importante refere-se às tradições do pensamento marxista. Louis Althusser afirmou que, ao colocar as relações sociais (modos de produção, exploração da força de trabalho, os circuitos do capital) e não uma noção abstrata de homem no centro de seu sistema teórico, Marx deslocou duas proposições-chave da filosofia moderna: que há uma essência universal de homem e que essa essência é o atributo de "cada indivíduo singular" (sujeito real). A segunda grande ruptura no pensamento 
ocidental do século XX vem da descoberta do inconsciente por Freud. A teoria freudiana desmonta o conceito de sujeito cognoscente e racional de uma identidade fixa e unificada.

A terceira ruptura está associada ao trabalho do linguista Ferdinand Saussure, para quem nós não somos, em nenhum sentido, os autores das afirmações que fazemos ou dos significados que expressamos na língua. Utilizamos essa forma para reproduzir significados apenas nos posicionando no interior das regras da língua e dos sistemas de significados da nossa cultura. Além disso, os significados das palavras não são fixos, surgem nas relações de similaridade e diferença que as palavras têm com outras palavras, no interior do código da língua. Como quarta ruptura observa-se o trabalho de Michel Foucault, que destaca um novo tipo de poder, "o poder das disciplinas", cujo objetivo é produzir um ser humano que possa ser tratado como um corpo dócil.

A quinta ruptura seria o impacto do feminismo, tanto como crítica teórica quanto como movimento social, no questionamento político da sexualidade e da divisão doméstica do trabalho, politizando a subjetividade e o processo de identificação. Se for possível falar em exemplaridade em relação a essas rupturas é porque suas práticas diluidoras de paradigmas propiciam, sob o eixo da fragmentação, a instauração de novos caminhos para a leitura da História, projetando redefinições da concepção de sujeito e de sua relação com o objeto de estudo. Dentro desse quadro, tudo conspira para o deslocamento complexo de um campo teórico para outro, como modos de construir sentidos, que organizam as concepções na mesma proporção das ações do homem, num tempo e num espaço que denominamos Histórico.

Vislumbra-se um diálogo inovador e radical com a História que já não se contenta com a mera representação do verossímil. Não se trata mais de textos que tangenciam o histórico pela utilização de informações verídicas que são objetos da história, mas de um discurso organizador da história por meio da ficção, eliminando barreiras entre os dois campos, insistindo no estabelecimento de elos de comunhão. Estamos próximos de uma perspectiva que faz interagir os dois discursos. As fronteiras entre um e outro são tênues, e, por causa disso, começam a diluir-se.

A dispersão do sujeito, a desconstrução da linguagem, o descrédito na acumulação minemônica geram, em nosso tempo, o (des)entendimento que a ficção e a História não podem ser avaliadas, nos limites discursivos, como constituição de verdades ou de mentiras. A História e a fábula se tocam e se trocam em figurações metafóricas ou metonímicas que conciliam o real e o imaginário, configurando a impossibilidade da reconstrução de um realpassado sem o transpassar de um processo discursivo.

Pela mesma lógica é possível afirmar que a literatura, enquanto força de representação discursiva, captura no viés imaginativo as margens dos discursos hegemônicos, entalhados nos interstícios das instituições e nas brechas dos aparelhos de poder e de conhecimento. Adorno (1988 p.16) já afirmava que "os antagonismos não resolvidos da realidade retornam às obras de arte como os problemas imanentes de sua forma”.

A narrativa alcança uma posição privilegiada no mundo cultural porque permite uma representação tanto da sincronia quanto da diacronia, das continuidades estruturais e dos 
processos pelos quais aquelas continuidades se desenvolvem e se recompõem no tipo de produção de significado que encontramos em registros, tais como as novelas.

Geografia, território e lugar são categorias entrecruzadas de uma certa maneira de experienciar o espaço na modernidade, a partir de uma nova lógica:

Geografias reais de ação social, territórios e espaços de poder reais e metafóricos que se tornam vitais como forças organizadoras na geopolítica do capitalismo, ao mesmo tempo em que é sede de inúmeras diferenças e alteridades que têm que ser compreendidas tanto por si mesmas como no âmbito da lógica global do desenvolvimento capitalista (HARVEY, 1993, p.321).

David Harvey (1993, p.237) estuda a experiência da compressão tempo e espaço na vida social privilegiando os vínculos materiais entre os processos político-econômicos e os processos culturais, como tentativa de apreender a multiplicidade e a complexidade que essas instâncias podem exprimir, bem como o papel das práticas humanas em sua construção. Em consequência, para ele, cada formação social incorpora um agregado particular de práticas e conceitos em relação ao tempo e ao espaço.

As teorias sociais, cujo foco foi sempre os processos de mudança social, da modernização e da revolução elegeram o progresso como seu objeto teórico e o tempo histórico como sua dimensão básica. O primeiro implica, com efeito, a conquista do espaço, mas enfatizando a temporalidade (vir a ser) em vez do espaço e do lugar (do ser). A teoria cultural preocupa-se mais com a "espacialização do tempo". A invenção da imprensa lembra Harvey (1993, pg 191), mergulhou a palavra no espaço ao abstrair propriedades do fluxo da experiência e fixá-las em forma espacial. Em contraponto à dominante temporalidade do alto modernismo, a contemporaneidade aposta na pura experiência de um presente espacial, no escrever o tempo, exigindo interpretações mediadas por novas categorias teóricas ou, pelo menos, a partir de categorias "sob rasura". "

Para Stuart Hall (2004), os argumentos de Harvey são importantes porque o tempo e o espaço são coordenadas básicas de todos os sistemas de representação, e diferentes épocas culturais têm diferentes formas de combinar as coordenadas espaço-tempo. Invocando Giddens (1990, p.72), Hall separa "lugar" de "espaço", categorias coincidentes nas sociedades pré-modernas - "uma vez que as dimensões espaciais da vida social eram, para a maioria da população, dominadas pela presença - por uma atividade localizada.” (GIDDENS apud Hall, 2001, p.72). O "lugar" é concreto, delimitado, familiar, fixo, "ponto de práticas sociais específicas que nos moldaram e nos formaram e com as quais nossas identidades estão

\footnotetext{
1 "Stuart Hall referenda a perspectiva desconstrutivista e coloca certos conceitos sob o sinal de rasura no sentido de que indica que eles não servem mais - não são mais 'bons para pensar'. Mas uma vez que eles não foram dialeticamente superados e que não existem outros conceitos, inteiramente diferentes, que possam substituí-los, não existe nada a fazer senão continuar a pensar com eles - embora agora em suas formas - não se trabalhando mais no paradigma no qual eles foram originalmente gerados". "Quem precisa de identidade". In: SILVA, Tomaz Tadeu et al. (Org.) Identidade e diferença. Petrópolis: Vozes, 2004, p. 104.
} 
estreitamente ligadas" (HALL, 2004, p. 72). O espaço implica na sua dimensão ampla, possibilidades sensíveis, ligando-se, então, a categorias temporais.

Essas questões possibilitam pensar a articulação entre relações sociais e estruturas espaciais e, mais especificamente, articular as topologias do simbólico aos princípios da realidade atravessados pela complexidade da relação tempo/espaço.

Bauman (2001), partindo do princípio de que cada formação social promove seu tipo de racionalidade e de que a "modernidade é o tempo em que o tempo tem uma história" (BAUMAN, 2001, p.129) associa o começo da era moderna à várias facetas das práticas humanas em mudança:

a emancipação do tempo em relação ao espaço, sua subordinação à inventividade e à capacidade técnica humana e, portanto, a colocação do tempo contra o espaço como ferramenta da conquista do espaço e da o território estava entre as mais apropriação de terras não são um momento pior para começar uma avaliação de qualquer outro ponto de partida (...) a conquista do espaço veio a significar máquinas mais velozes. $\mathrm{O}$ movimento acelerado significava maior espaço, e acelerar o movimento era o único meio de ampliar o espaço. Nessa corrida, a expansão espacial era o nome do jogo e o espaço, seu objetivo: o espaço era valor, o tempo, a ferramenta (BAUMAN, 2001, p.129).

E, finalmente, conclui que:

poder-se-ia dizer que a diferença entre os fortes e os fracos é a diferença entre um território formado como no do mapa - vigiado de perto e estritamente controlado - e um território aberto à invasão, ao redesenho das fronteiras e à projeção de novos mapas. Pelo menos foi isso que se tornou assim e assim permaneceu por boa parte da história moderna ( BAUMAN, 2001, p.136).

Bauman denomina esta parte da história de "Modernidade pesada", obcecada pelo volume, pelo "quanto maior, melhor", "tamanho é poder", cujo objetivo supremo era preencher o espaço, marcando-o com sinais tangíveis de posse. Daí que:

agudas obsessões modernas e sua aquisição, entre as urgências mais prementes - enquanto a manutenção das fronteiras se tornava um de seus vícios mais oblíquos, resistentes e inexoráveis. A modernidade pesada foi a era da conquista territorial (BAUMAN, 2001, p.132).

A riqueza e o poder dependem do tamanho, de medidas de volume e peso, sendo o lugar seu repositório e fortaleza. O lugar é a forma fixa da lógica do poder e do controle fundado na estrita separação entre o "dentro" e o "fora" e na vigilante defesa da fronteira entre eles. Na versão pesada da Modernidade, diz Bauman, o progresso significava tamanho crescente e expansão espacial. A fortificação do espaço conquistado, sua colonização e domesticação dependiam de um tempo rígido, uniforme e inflexível - o que Bauman qualifica como "amansar o tempo", rotinizá-lo, prendendo o trabalho ao solo enquanto nos prédios das fábricas, o peso do maquinário acorrentava o capital. 
No viés de Harvey (1993, p.189), “a história dos conceitos de tempo, espaço e tempoespaço na física tem sido marcada, na verdade, por fortes rupturas e reconstruções epistemológicas". A ideia de tempo-espaço não é recente, nem menos contraditória. Aristóteles, Santo Agostinho, Bergson, Galileu, Newton e Einstein estudaram e conceituaram tais elementos. No século XIX, os cientistas acreditavam que a Física deveria se debruçar sobre experimentos que pudessem explicar a ação das forças sobre as partículas de matérias da mesma forma que essas se movem mediante a ação das forças.

$\mathrm{Na}$ sociedade capitalista, por excelência, o tempo e o espaço formam um nexo substancial de poder social. Foucault (1992, p. 231) dizia que o espaço é sempre um contingente de poder social e, portanto, a reorganização do espaço é sempre uma reorganização da estrutura mediante a qual o poder social é expresso. Harvey (1993, p.207) inclusive situa a questão temporalmente "a partir dos anos 70, vem ocorrendo algo vital para a nossa experiência do espaço e do tempo que provocou a virada para o pós-modernismo". Este "algo" vital pode ser sintetizado pelo termo "globalização", um complexo de processos e forças de mudanças atuantes numa escala global que atravessam fronteiras nacionais, integrando e conectando comunidades e organizações em novas combinações de tempo e espaço, tornando o mundo em realidade e em experiência, mais interconectado.

A globalização implica um movimento de distanciamento da ideia sociológica clássica da "sociedade" como um sistema bem delimitado e sua substituição por uma perspectiva que se concentra na forma como a vida social está ordenada ao longo do tempo e do espaço. Essas novas características temporais e espaciais, estão entre os aspectos mais importantes da globalização a ter efeito sobre as identidades culturais (HALL, 2004, pg 75).

Stuart Hall (2004, p.68) lembra que a globalização não é um fenômeno recente e ratifica a assertiva de Giddens (1990, p.63) de que a modernidade é inerentemente globalizante já que o capital nunca permitiu que os estados-nação fossem tão autônomos ou soberanos como pretendiam, de forma que tanto a tendência à autonomia nacional quanto a tendência à globalização estão profundamente enraizadas na modernidade. No entanto, a partir dos aludidos anos 70, tanto o alcance quanto o ritmo de integração global aumentaram acelerando os fluxos e os laços entre as nações. As consequências contraditórias desses aspectos da globalização sobre as identidades culturais são apontadas por Hall:

- as identidades nacionais estão se desintegrando, como resultado do crescimento da homogeneização cultural e do "pós-moderno" global;

- as identidades nacionais e outras identidades "locais" ou particularistas estão sendo reforçadas pela resistência à globalização;

- as identidades nacionais estão em declínio, mas novas identidades - híbridas - estão tomando seu lugar (HALL, 2004, p.26).

No mundo pós-moderno, a cultura e a vida social estão estreitamente aliadas, na forma da estética da mercadoria, na especularização da política e no consumo como estilo de vida. A integração da cultura dentro dessa lógica, em geral, se dá por meio de uma forte valorização para o mundano. 


\section{4) Considerações finais: Encaminhamentos epistemológicos}

Em meio a esse quadro, a crítica cultural e a teoria da cultura emergem como discursos possíveis para o enfrentamento das produções simbólicas advindas de outros lugares e servem como representações históricas do sujeito concreto e enraizado nas práticas sociais. Nesse sentido, é necessário refletir sobre a construção/ (des)construção das identidades que se constituem nos textos, na história e na política, uma vez que resultam de formas subjetivas cujas produções simbólicas estão atravessadas, no dizer de Hall(2004, p. 87), por diferentes divisões e antagonismos.

A difusão de consumismo (como realidade ou sonho), o efeito de supermercado global constituído no seu interior e as distinções e diferenças culturais, que até então definiam a identidade, ficam reduzidas a uma espécie de língua franca internacional. Nesses termos, todas as tradições específicas e as diferenciações identitárias podem ser traduzidas sob o impacto e como consequência da homogeneização cultural, um complexo fenômeno que implica a inevitável mercantilização da etnia e da alteridade.

É inegável que as negociações identitárias pressupõem e permitem escolhas de identidade mais amplas no centro do sistema global em comparação as periferias. Estabelecese assim um padrão de trocas desiguais, pois sociedades periféricas, mais do que nunca, estão abertas as influências culturais centro-ocidentais, em função de que o processo globalizador retêm aspectos de dominação sem fronteiras. Imerso a esse efeito percebe-se que, ao movimento para fora, realizado pelo centro (de mercadorias, de imagens, estilos e identidades consumistas), corresponde um enorme deslocamento de pessoas, transitando das margens para o centro. Impulsionados pela pobreza, guerras, distúrbios políticos e conflitos regionais, as pessoas mais pobres do globo acabam incorporando a mensagem do consumismo global e se mudam para os lugares onde estão os bens, constituindo assim um tipo de migração sem precedentes históricos.

O entrecruzamento entre cultura, identidade e memória instiga uma série de reflexões sobre a formação e determinação histórica do sujeito e suas representações, particularmente daqueles cujas narrativas simbólicas foram silenciadas. Acionado pela emancipação da memória, tais traços tornam consciente o que o esquecimento, em sua capacidade de impor um limite ao conhecimento, suprimiu da lembrança.

\section{Referências Bibliográficas}

ADORNO, Theodor Teoria Estética. Lisboa: Martins Fontes, 1988.

BAUMAN, Zygmunt. Modernidade líquida. Rio de Janeiro: Jorge Zahar, 2001.

Identidade: entrevista a Benedetto Vecchi. Rio de Janeiro: Jorge Zahar, 2005. 
BENJAMIN, Walter. A Obra de Arte na Época de sua Reprodutibilidade Técnica. In: LIMA, Luiz Costa (Org.). Teoria da Cultura de Massa. Rio de Janeiro: Paz e Terra, 1978.

CAMPOS, Maria do Carmo; INDURSKY, Freda. (Org.). Discurso, Memória, Identidade. Ensaios 15. Porto Alegre: Sagra Luzzatto, 2000.

CANDIDO, Antônio A Educação pela noite e outros ensaios. São Paulo: Ed. Ática, 1987.

CATROGA, Fernando. Memória, História e Historiografia. Coimbra: Tipografia Arte Pronta, 2000.

EAGLETON, Terry Teoria da Literatura: uma introdução. São Paulo: Martins Fontes, 1983. ,Terry.A Ideia de cultura.São Paulo:Editora UNESP, 2005.

FALCON, Francisco J. Calazans. História e Representação. In: Revista História das Idéias (História e Literatura), Coimbra, v. 21, p.87-126, 2000.

FOUCAULT, Michel. Microfísica do Poder. Rio de Janeiro: Graal, 1992.

GIDDENS, Antony. Modernidade e identidade pessoal. Vieiras: Celta Editora, 1997. . O mundo na era da globalização. Lisboa: Editorial Presença, 2000.

HALL, Stuart. A Identidade Cultural na Pós-Modernidade. Rio de Janeiro: DP\&A, 2004. Quem precisa de identidade. In: SILVA, Tomaz Tadeu (Org.). Identidade e diferença. Petrópolis: Vozes, 2005.

HARVEY, David. Condição Pós-Moderna. São Paulo: Edições Loyola, 1993.

JAMESON, Fredric. O Inconsciente Político - a Narrativa como ato socialmente simbólico. São Paulo: Ática, 1992.

UNESP, 1997.

O Marxismo Tardio: Adorno ou a persistência da dialética. São Paulo:

SILVA, Tomaz Tadeu da (org.)O Que é, afinal, Estudos Culturais? Belo Horizonte: Autêntica, 2004.

. (org). Identidade e Diferença - a perspectiva dos Estudos Culturais.

Petrópolis: Editora Vozes, 2004.

VECCHI, Roberto. Barbárie e representação: o silêncio da testemunha. In: PESAVENTO, Sandra J. Fronteiras do milênio. Porto Alegre: Ed. da UFRGS, 2001. 